\title{
Práticas de cuidado à saúde de mulheres camponesas
}

\author{
Iraí Maria de Campos Teixeira ${ }^{(a)}$ \\ Maria Waldenez de Oliveira(b)
}

Teixeira IMC, Oliveira MW. Health care practices of peasant women. Interface (Botucatu). 2014; 18 Supl 2: 1341-1354.

This study presents the results of research on the health care practices of peasant women in Monte Alegre Settlement VI - SP. A qualitative method was adopted, comprising participant observation and individual and collective interviews during the 15 visits from April 2010 to July 2011. Twelve residents participated, of whom six were community health agents. Health care practices refer to companionship, dialogue, active listening, social mobilization, multidisciplinary health services assistance, use of medicinal plants, religious belief as social support, and diet. Such practices were added up and articulated. The participants shared and learnt regarding health care practices from each other. The interactions and learning were intergenerational and from health professionals, besides other sources of information and specific training processes such as the Program of Family Health (PSF).

Keywords: Popular education and health. Health care. Rural health. Popular health practices. Educational processes.
O presente artigo apresenta resultados de pesquisa acerca de práticas de cuidado à saúde de mulheres camponesas do Assentamento Monte Alegre VI - SP. A metodologia, qualitativa, constou de observação participante, entrevistas individuais e coletivas, tendo ocorrido 15 visitas no período de abril de 2010 a julho de 2011. Participaram doze moradoras, das quais, seis agentes comunitárias de saúde. As práticas de cuidado à saúde referem-se a: companheirismo, diálogo, escuta ativa, mobilizações sociais, assistência multiprofissional dos serviços de saúde, uso de plantas medicinais, crença religiosa como apoio social e dietas. Tais práticas somam-se e articulam-se. As participantes ensinam e aprendem sobre o cuidado à saúde nas relações entre elas, nas intergeracionais e nas com os profissionais de saúde, além de recorrerem a outras fontes de informação e outros processos formativos específicos, como do Programa Saúde da Família.

Palavras-chave: Educação popular e saúde. Cuidado à saúde. Saúde da população rural. Práticas populares de saúde. Processos educativos. 


\section{Introdução}

Ayres ${ }^{1}$ discute o cuidado à saúde no contexto da saúde pública, definindo cuidado como a "conformação humanizada do ato assistencial". O termo cuidado designa

uma atenção à saúde imediatamente interessada no sentido existencial da experiência do adoecimento, físico ou mental, e, por conseguinte, também das práticas de promoção, proteção ou recuperação da saúde'.

Essa compreensão de cuidado requer uma "dimensão ampliada da compreensão das condições de vida, considerando a individualidade dos atores, sem perder de vista o coletivo, o meio social em que vivem e se identificam" 2 .

Nessa perspectiva, encontramos o ato de cuidar na luta dos oprimidos, marginalizados ${ }^{3,4}$, bem como este se mostra

visível no trabalho das parteiras tradicionais, nas práticas de saúde que ocorrem nos terreiros de candomblés, no acolhimento e na escuta que os erveiros e raizeiros dispensam a quem os procuram, nos benzedores, na religiosidade, enfim, o cuidar do Outro é um constante exercício de solidariedade que afirma cotidianamente a possibilidade de afirmação da vida ${ }^{5}$.

Referindo-se ao cuidado à saúde da mulher, Coelho et al. ${ }^{6}$ afirmam que

o cuidado deve ser permeado pelo acolhimento com escuta sensível de suas demandas, valorizando-se a influência das relações de gênero, raça/cor, classe e geração no processo de saúde e de adoecimento das mulheres.

Acrescente-se que, no contexto da luta pelo direito à terra, uma influência adicional que necessita ser também valorizada: a luta pelo reconhecimento da profissão de trabalhadora rural e, com isso, dos direitos previdenciários das mulheres do campo. O trabalho feminino no campo muitas vezes não é visto como uma atividade que gera riqueza ${ }^{7}$, principalmente quando se trata da participação das mulheres na agricultura familiar. Em todo Brasil, mulheres trabalhadoras rurais produzem alimentos e garantem a subsistência da família desenvolvendo trabalhos no roçado, além de se ocuparem com o plantio de ervas medicinais e com o artesanato. Segundo Sales $^{7}$, o fato desse trabalho não ter o devido reconhecimento econômico, tanto no interior da família como nos sindicatos e órgãos públicos, inviabilizou, durante muito tempo, o reconhecimento destas mulheres como trabalhadoras e, consequentemente, a garantia de seus direitos sociais. A luta pelo direito à saúde é um marco fundamental do processo de resistência e dinamismo do trabalho de base das mulheres camponesas ${ }^{8}$.

Grupos populares (como os de mulheres camponesas), segundo Minayo $^{9}$, possuem uma interpretação das doenças baseada em um contexto pluridimensional que inclui causas naturais, sobrenaturais, psicossociais e socioeconômicas. Suas práticas de saúde, se comparadas às baseadas na biomedicina, possuem uma visão mais integral para a saúde e para a doença, pois

enquanto a intervenção médica oficial pretende apenas fornecer uma explicação experimental dos mecanismos químico-biológicos da morbidez e dos meios eficazes para controlá-los, as medicinas populares associam uma resposta integral a uma série de insatisfações (não apenas somáticas, mas psicológicas, sociais, espirituais para alguns, existenciais para todos) que o racionalismo social não se mostra disposto a eliminar ${ }^{10}$. 
Foi o que encontrou a pesquisadora Scopinho ${ }^{11}$, ao investigar tais práticas em trabalhadores rurais de um assentamento ${ }^{(c)}$. Segundo a autora, esses trabalhadores recorriam a um conjunto de práticas para cuidar da saúde que incluíam desde a busca de atenção nos serviços localizados no entorno até as práticas religiosas, passando pelo uso de plantas medicinais e pelas propostas que valorizam as atividades socioculturais, o lazer e o esporte.

A cultura popular, muitas vezes iletrada, é legítima e corresponde às estruturas materiais e simbólicas do povo. Contudo, essa cultura é ignorada, negada e considerada analfabeta por sua simbologia não ser compreendida pela cultura do centro, dominante ${ }^{12}$. A ciência produzida no hemisfério norte, ou sob suas bases epistemológicas, contém escolhas que favorecerão a cultura dominante, tanto politicamente como economicamente e, finalmente, culturalmente, sendo a ciência "o mais sutil instrumento de dominação"12 ao direcionar sua produção de conhecimento sempre à manutenção do seu domínio. Para permanecer dominante, portanto, desqualifica o conhecimento produzido fora do seu escopo.

As práticas populares de saúde

foram submetidas a essa mesma concepção, sendo entendidas pela sociedade como atraso e ignorância, contrastando com as práticas médicas, estas tidas como dotadas de cientificidade e legitimidade. [...] Incorporou-se, historicamente, a prática médica com a tal prática científica e, conseqüentemente, desqualificaram-se outras práticas e praticantes ${ }^{13}$.

Em sua investigação sobre agentes de cura, Queiroz ${ }^{14}$ encontrou que as mulheres exercem papel de destaque no universo das práticas populares de saúde. São elas as principais praticantes populares de saúde no interior das famílias e as principais responsáveis pela passagem dos conhecimentos pertinentes às práticas populares de saúde, geração após geração, desempenhando também os papéis de cuidadoras e provedoras do bem-estar no interior das famílias.

No que se refere à terapêutica e à família, Oliveira e Moraes ${ }^{13}$ destacam que "a mulher, mãe ou esposa mais especificamente, atuam no processo terapêutico ao providenciarem os primeiros cuidados de saúde", uma vez que

a mulher, exercendo o papel de personagem principal no cuidado e encaminhamento dos problemas de saúde familiares, avalia a necessidade de providenciar o cuidado ao familiar ou não e, quando houver necessidade deste, qual dos agentes de saúde deverá ser procurado. ${ }^{13}$

As autoras destacam ainda que outro aspecto a ser considerado ao se examinar as mulheres e as práticas populares, é o fato de que:

Embora haja variações entre diferentes práticas, os estudos analisados para este trabalho apontam que a mulher tem sido a que mais frequentemente está à frente de determinadas práticas populares alternativas tais como as parteiras, as benzedeiras e a direção de terreiros e as posições elevadas na "hierarquia eclesiástica" das mães-de-santo na Umbanda e no Candomblé13.

Há outras práticas populares de saúde que não se encontram relacionadas nem às intervenções terapêuticas propriamente ditas, nem às práticas de formulação política, "mas representam formas de empoderamento dos indivíduos e dos coletivos por meio de atividades lúdicas, tais como as danças e as rodas" 5 . Estas manifestações representam formas de explicar os processos de adoecimento, sofrimento e as práticas que trazem, em seu bojo, maneiras de promover a saúde, prevenir as doenças e de cuidar daqueles que adoecem e dos que precisam de maior proteção. (c) Assentamento refere-se à instalação de novas propriedades agrícolas, por meio de políticas governamentais, uma redistribuição de terras menos concentradora, cujos envolvidos são os trabalhadores rurais semterra ${ }^{4}$. 


\section{Metodologia}

Nesse artigo apresentam-se resultados de pesquisa ${ }^{15}$ cujos objetivos foram conhecer a compreensão atribuída por mulheres camponesas à saúde e identificar as práticas sociais de cuidado com a saúde, bem como os processos educativos por elas desencadeados ${ }^{(\mathrm{d})}$. O presente artigo foca especificamente as práticas de cuidado à saúde de mulheres camponesas.

O local onde se desenvolveu a pesquisa foi o Assentamento Monte Alegre/ Núcleo VI, no interior do estado de São Paulo. O Assentamento Monte Alegre encontra-se dentro do limite de três municípios: Araraquara, Matão e Motuca (SP). Suas primeiras áreas de assentamentos (Monte Alegre 1, 2, 3 e 4) foram instaladas nos anos de 1985 e 1986, tendo sido completadas quase dez anos depois ${ }^{16,17,18}$. Vivem e trabalham no assentamento 385 famílias $^{16,18}$.

Durante o período de 1995 a 1998 foi formado o Monte Alegre VI, atualmente com 96 lotes. Este é o maior dos núcleos, com uma área de 1.254 hectares. Possui um galpão onde atuam a equipe do Programa Saúde da Família (PSF) e um Centro Comunitário. Há uma escola de ensino fundamental e supletivo, porém não há creche, pré-escola ou ensino médio (estes últimos, quando necessário, são acessados em cidades vizinhas) ${ }^{15}$.

Optou-se, metodologicamente, por uma abordagem qualitativa ${ }^{9}$. Esta opção exigiu um exame do mundo circundante "com a ideia de que nada é trivial, que tudo tem potencial para constituir uma pista que nos permita estabelecer uma compreensão mais esclarecedora do nosso objeto de estudo" 19 .

Utilizou-se da observação participante que possibilita formas de interação entre o pesquisador e os sujeitos, permitindo uma abordagem pessoal e abrindo fontes de informaçãa ${ }^{20}$. A observação participante é

aquela na qual o pesquisador se integra à realidade que pretende observar, convertendo-se em um a mais do grupo social objeto de estudo. Nela se favorece a intersubjetividade, incluindo ao investigador. Busca descobrir o sentido, a dinâmica e os processos dos acontecimentos que se dão em um determinado contexto social desde o ponto de vista dos participantes ${ }^{21}$.

Os dados foram coletados no período de abril de 2010 a julho de 2011. Foram feitas 15 (quinze) visitas ao assentamento onde se realizaram as observações, com posteriores anotações em diário de campo. Para o trabalho de campo, realizou-se uma cuidadosa inserção que possibilitou conhecimento mútuo, pesquisadora e mulheres da Associação de Mulheres Assentadas do Assentamento Monte Alegre $\mathrm{VI}$, em seu ambiente de trabalho, a padaria do núcleo seis do assentamento.

A aproximação e a apresentação da pesquisa ocorreram em uma primeira visita à padaria. A participação posterior da pesquisadora no trabalho da padaria, durante o período de coleta de dados, possibilitou sua inserção no campo de pesquisa e a criação dos vínculos que enriqueceram o trabalho. A aproximação com as agentes comunitárias de saúde aconteceu posteriormente a esta inserção na padaria, a partir de um convite à associada Preta ${ }^{(e)}$, que é agente comunitária de saúde, para participar da pesquisa. O convite se estendeu para as demais agentes comunitárias, moradoras do assentamento, que convidaram outras mulheres de seu convívio. Foram convidadas a participar da pesquisa todas as mulheres da Associação, que, por sua vez, estenderam o convite às mulheres do assentamento que exerciam práticas de saúde (populares ou não) e/ou que fossem engajadas nas atividades de melhoria das condições de saúde dos assentados, totalizando 12 (doze) participantes. (d) Projeto aprovado pelo Comitê de Ética da Universidade Federal de São Carlos.

(e) Mantivemos os nomes reais por uma escolha das participantes que pediram para que suas histórias pessoais fossem divulgadas e suas lutas reconhecidas por aqueles que lessem os resultados dessa pesquisa. 
Na tabela 1, encontram-se informações mais detalhadas das mulheres participantes da pesquisa ${ }^{(f)}$. Das doze participantes, seis compõem a Associação de Mulheres do Assentamento Monte Alegre, seis são agentes comunitárias de saúde - ACS da Equipe de Saúde da Família do assentamento (sendo que uma destas é participante da associação e também agente comunitária de saúde no assentamento junto à mesma equipe) e uma é moradora do núcleo seis, trabalhadora do lar, usuária do serviço de Atenção à Saúde da Família e participante dos grupos e eventos organizados pela associação. Todas são assentadas e trabalham nos sítios, se dedicando ao roçado e à criação de animais, além dos cuidados domésticos como limpeza da casa e preparo de alimentos. $\mathrm{Na}$ tabela, incluímos o trabalho no sítio apenas para aquelas que se referiram a este trabalho como significativo na geração da renda familiar.

(f) Alguns dados não constam no quadro síntese que descreve as participantes da pesquisa porque tais dados foram obtidos ao longo das visitas, sendo que nem todas forneceram as mesma informações sobre si.

Tabela 1. Síntese descritiva das mulheres camponesas, colaboradoras da pesquisa.

\begin{tabular}{|c|c|c|c|c|c|c|}
\hline Nome & Idade & Naturalidade & Escolaridade & Ocupação & $\begin{array}{l}\text { Estado } \\
\text { Marital }\end{array}$ & $\begin{array}{c}\text { Filhos e outros } \\
\text { familiares sob seus } \\
\text { cuidados }\end{array}$ \\
\hline Maria José & 54 anos & $\begin{array}{l}\text { Campo Morão - } \\
\text { Paraná }\end{array}$ & $\begin{array}{l}\text { Fundamental } \\
\text { incompleto }\end{array}$ & $\begin{array}{c}\text { Trabalha no sítio, } \\
\text { na panificadora e é } \\
\text { associada }\end{array}$ & \multicolumn{2}{|c|}{$\begin{array}{l}\text { Casou com } 18 \text { anos e após um ano } \\
\text { e meio ficou viúva. Nessa época já } \\
\text { tinha três filhos. Aos } 22 \text { anos casou- } \\
\text { se novamente e teve mais três filhos. } \\
\text { Seu marido já tinha seis filhos, de } \\
\text { modo que Maria criou } 12 \text { filhos. }\end{array}$} \\
\hline $\begin{array}{l}\text { Elizete } \\
\text { (Zete) }\end{array}$ & $\begin{array}{l}\text { Não foi } \\
\text { informado }\end{array}$ & $\begin{array}{l}\text { Nasceu no estado } \\
\text { de São Paulo, mas } \\
\text { cresceu no Paraná }\end{array}$ & $\begin{array}{l}\text { Fundamental } \\
\text { incompleto }\end{array}$ & $\begin{array}{l}\text { Trabalha no sítio, } \\
\text { na panificadora e é } \\
\text { associada }\end{array}$ & Casada & $\begin{array}{c}\text { Dois filhos e uma } \\
\text { filha. }\end{array}$ \\
\hline Jisele & 43 anos & Interior da Bahia & $\begin{array}{l}\text { Ensino médio } \\
\text { completo }\end{array}$ & $\begin{array}{l}\text { Trabalha no sítio, } \\
\text { na panificadora e é } \\
\text { associada }\end{array}$ & Casada & $\begin{array}{l}\text { Uma filha, um filho, } \\
\text { uma neta e um neto. }\end{array}$ \\
\hline Zilda & $\begin{array}{l}\text { Não foi } \\
\text { informado }\end{array}$ & Não foi informado & $\begin{array}{l}\text { Fundamental } \\
\text { incompleto }\end{array}$ & $\begin{array}{l}\text { Trabalha no sítio, } \\
\text { na panificadora e é } \\
\text { associada }\end{array}$ & Casada & Não foi informado \\
\hline Preta & 45 anos & $\begin{array}{l}\text { Riolandia - interior } \\
\text { de São Paulo }\end{array}$ & $\begin{array}{l}\text { Ensino médio } \\
\text { completo }\end{array}$ & $\begin{array}{l}\text { Trabalha no sítio, é } \\
\text { ACS e é associada }\end{array}$ & Casada & Não têm filhos. \\
\hline Marli & 43 anos & ABC Paulista & $\begin{array}{l}\text { Ensino médio } \\
\text { completo }\end{array}$ & ACS & Casada & Tem três filhos. \\
\hline Fran & 16 anos & $\begin{array}{c}\text { Nasceu no } \\
\text { assentamento }\end{array}$ & $\begin{array}{c}\text { Está cursando o } \\
\text { ensino médio em } \\
\text { Matão }\end{array}$ & $\begin{array}{l}\text { Estudante, auxilia } \\
\text { nos trabalhos da } \\
\text { padaria quando } \\
\text { está no período das } \\
\text { férias escolares }\end{array}$ & Solteira & Não têm filhos. \\
\hline Flávia & 32 anos & $\begin{array}{l}\text { Araraquara - } \\
\text { interior de São } \\
\text { Paulo }\end{array}$ & $\begin{array}{l}\text { Ensino médio } \\
\text { completo }\end{array}$ & ACS & Casada & Têm dois filhos. \\
\hline Vanda & 33 anos & $\begin{array}{l}\text { Boa Esperança do } \\
\text { Sul - interior de } \\
\text { São Paulo }\end{array}$ & $\begin{array}{l}\text { Ensino médio } \\
\text { completo }\end{array}$ & ACS & Casada & Não foi informado \\
\hline Marlene & 35 anos & Paraná & $\begin{array}{l}\text { Fundamental } \\
\text { incompleto }\end{array}$ & $\begin{array}{c}\text { Trabalha no sítio, } \\
\text { na panificadora e é } \\
\text { associada }\end{array}$ & $\begin{array}{l}\text { Não foi } \\
\text { informado }\end{array}$ & Não foi informado \\
\hline Leonilda & 33 anos & Não foi informado & $\begin{array}{l}\text { Ensino médio } \\
\text { completo }\end{array}$ & ACS & Casada & Têm três filhos. \\
\hline Regina & $\begin{array}{l}\text { Não foi } \\
\text { informado }\end{array}$ & $\begin{array}{l}\text { Sertãozinho - } \\
\text { interior do estado } \\
\text { de São Paulo }\end{array}$ & Não foi informado & Trabalha no sítio & Separada & Têm dois filhos. \\
\hline
\end{tabular}


Realizaram-se algumas conversas individuais - na maioria das vezes nas próprias residências das mulheres e, costumeiramente, durante a apreciação de um bom café ou almoço - e uma entrevista coletiva. Os dados coletados foram submetidos à análise temática, considerando-se três etapas básicas: pré-análise, exploração do material, tratamento dos dados obtidos e interpretação $0^{9,22}$.

\section{O cuidado nas práticas de saúde das mulheres camponesas}

Ao definirem o cuidado, as mulheres iniciam suas falas referindo-se aos cuidados com a saúde do corpo, citando os cuidados com a higiene, a alimentação, as atividades físicas e a busca por assistência nas unidades de saúde. Seguindo, identificam também a escuta, as demonstrações de afeto, a atenção e o carinho como práticas desse cuidado.

Identificamos o companheirismo como uma das formas de cuidado mais evidente nas falas, seguido do diálogo. Chamamos de companheirismo a prática de ir ao encontro da outra ou do outro que está em sofrimento, para ajudá-la ou ajudá-lo, oferecendo conforto emocional ou psicológico.

Ela mesma é prova de que esses encontros funcionam. Quando começou o programa, eu ia na casa dela e ela só queria morrê [...] Aí, através da gente se unir, começamos se unir, ela conseguiu. A primeira pessoa que nós falamos, ela não pode ficar fora da padaria, foi a Maria. Ela tem que ocupar a cabeça dela [...]. Então hoje ela ta aí, tava com uma depressão lascada. (Preta)

Percebemos que o cuidado que elas praticam não se restringe ao grupo de mulheres, sendo um cuidado com a comunidade, com as pessoas que ali vivem; todas percebidas por elas como companheiras das lutas cotidianas. Esse companheirismo na luta cotidiana é discutido por Silva (2007) como lugar e processo de conscientização sobre as complexas determinações dos problemas sociais. $\mathrm{Na}$ formação educativa presente nas ocupações de luta pela terra, o conhecimento se constrói por meio

do estudo, da socialização, do diálogo da luta, da pesquisa, da reflexão, da análise, contribuindo para a formulação de uma nova consciência, capaz de redimensionar os sujeitos para que exercite novos valores do companheirismo, da partilha, honestidade, responsabilidade, do compromisso com a luta da classe trabalhadora, vivenciando a crítica e a autocrítica, fazendo uma reflexão das suas ações no espaço individual e coletivo ${ }^{23}$.

O diálogo, permeado pelo afeto característico do companheirismo, foi identificado junto às mulheres como cuidado que estimula a expressão dos sentimentos e a prática da escuta ativa.

Para Freire:

Ao fundar-se no amor, na humildade, na fé nas mulheres e nos homens, o diálogo se faz uma relação horizontal, em que a confiança de um polo no outro é consequência óbvia. Seria uma contradição se amoroso, humilde e cheio de fé, o diálogo não provocasse este clima de confiança entre seus sujeitos ${ }^{24}$.

Esse cuidado se dá com quem demonstra precisar de apoio, quando se isola ou quando busca atendimento médico para males emocionais ou psicológicos. Praticar a escuta ativa é uma forma de cuidar, de abrir-se ao diálogo ao se permitir cuidar e ser cuidada, numa ação recíproca.

Então esse é o cuidado! [...] É você cuidar! Trabalhar com o conteúdo, ouvir, saber falar, saber ouvir e saber responder. Eu vejo assim. (Preta)

Há um saber envolvido na escuta e na fala que responde, portanto, dialoga, não sendo o diálogo apenas um encontro físico entre as partes, como nos alerta Fiori ${ }^{25}$. É um encontro entre seres humanos 
que pronunciam e re-pronunciam um mundo, ou seja, "um ato de criação e recriação" ${ }^{26}$, um encontro que deve permitir que todos os sujeitos problematizem e pronunciem sua criação.

Muitos dos movimentos articulados pelo grupo de mulheres visam beneficiar toda a comunidade em que vivem e percebemos, nessas mobilizações, um cuidado com o próprio assentamento para que todas e todos tenham vidas dignas e saudáveis. As mobilizações e outras ações políticas são, portanto, consideradas nesta pesquisa como práticas de cuidado, uma vez que visam melhorias nos aspectos sociais determinantes da saúde, como apontado por elas. Percebe-se nas ações relatadas por elas, a dimensão coletiva do cuidado, como descrita por Daron ${ }^{8}$ :

As mulheres camponesas têm um jeito próprio de cuidar da vida e da saúde que se expressa nas práticas populares de cuidado que desenvolvem, articuladas com a luta para a garantia de um sistema público e universal de saúde e com um novo modo de viver no campo. Este modo singular de cuidado e de promoção da vida, saúde e cidadania, pode ser identificado como um processo educativo-terapêutico. Parte-se do pressuposto de que esse tipo de trabalho só pode ser realizado se for em grupo, com organização de base, trabalho coletivo e comunitário e o fazer com o que se tem, se sabe e se pode, sem depender de outros.

No conjunto de práticas utilizadas no cuidado à saúde oriundas do saber popular, identificamos como as práticas mais recorrentes no assentamento, a utilização de plantas medicinais, crença religiosa como apoio social, dietas como formas de tratamentos e a prática das parteiras.

Importante elucidar que as práticas populares de cuidado à saúde, assim como todas as demais práticas de cuidado, não ocorrem de maneira isolada das outras práticas, mas somam-se a elas numa busca por melhores soluções aos problemas enfrentados. Um exemplo disso são as parteiras, que utilizam outros recursos como rezas, chás e banhos nas suas práticas.

A minha avó, ela era parteira velha, e aí eu cresci vendo ela fazer, muita coisa eu não aprendi, eu faço uma coisa ou outra [...] Mas ela fazia muito essa xaropada, sabe, usava folha de pitanga, essas folhas, e dava certo, sabe. Dava certo! (Jisele)

Percebe-se na fala de Jisele o que Loyola ${ }^{27}$ encontrou em pesquisa sobre práticas populares de saúde: a maioria das mulheres que exerciam tais práticas adquiriu conhecimentos e incentivos a partir, principalmente, do contato com mulheres mais experientes, quase sempre pertencentes ao seu grupo familiar.

Com relação à dimensão espiritual, foram feitas menções sobre a Igreja Evangélica, que auxilia na educação dos filhos, afastando-os de conflitos com a lei.

[...] doze filhos eu criei, tudo na religião que era pra nós criar, nós era evangélico. Hoje eu não tenho nenhum filho que passou pela delegacia, não tenho nenhum filho que passou pela cadeia, nunca fui chamada em coisa, nunca fui chamada com problema deles [...] (Maria)

O uso de ervas medicinais é um recurso tradicional nas famílias, a maioria delas cultivadas nos quintais das casas, onde se encontram recursos selecionados e cultivados para o cuidado à saúde. $\mathrm{Na}$ cozinha são preparados os remédios naturais, com suas propriedades terapêuticas preventivas e curativas, e nela também se configura o lugar dos encontros e do preparo das refeições onde se prepara também o cafezinho. Seja no quintal, seja na cozinha, são inúmeros os aprendizados sobre cuidado e sobre ervas medicinais que se dão nas relações entre as mulheres.

Preta, que também é ACS, orienta as famílias a não deixarem de tomar os medicamentos receitados pela médica, porém ela mesma não usa nenhuma medicação farmacêutica, fazendo sempre uso de remédios naturais como chás e preparos feitos com as plantas que possui no quintal.

Há médicos que atuam no assentamento e que reconhecem a legitimidade dos tratamentos tradicionais aos quais suas mães, seus pais e avós recorriam e ainda fazem uso. Apesar de não se ter questionado as participantes especificamente sobre onde os profissionais aprenderam sobre as 
práticas, espontaneamente as mulheres referiram sobre esse aprendizado ter se dado no interior das famílias desses profissionais. Este dado nos remete a pesquisas que têm investigado a inserção do tema das práticas populares de saúde nos cursos profissionalizantes de nível superior, cujos resultados têm mostrado a lacuna na formação profissional ao mesmo tempo em que mostram o interesse dos estudantes no estudo dessa temática ${ }^{13}$.

As mulheres assentadas se referem a esse cuidado médico com admiração e valorizam essa postura do profissional.

Quando a gente tinha um médico aqui, até que já faleceu. Que o sonho dele era trabalhar com as plantas medicinais. De sair do posto e passar na horta e pegar o remédio. Em Itapeva funciona esse projeto e o sonho dele era colocar aqui no assentamento. Tanto aqui, e depois ele foi pro Bela Vista. (Preta)

Tem as mulheradas que tão no período da menopausa, elas tomam amora, chá de amora. Eu achei legal isso aí porque foi a própria Doutora que falou. (Marlene)

Marlene não atua profissionalmente na área da saúde e ficou satisfeita ao saber que a médica da saúde da família receita chás como tratamentos. Os mesmos chás usados antigamente dão resultados, além de não apresentarem os efeitos colaterais referidos pelas mulheres que usam, por exemplo, medicações para reposição hormonal durante esse período.

É, me passaram tudo isso pra mim. Eu engordei, inchei, chegava aqui com a boca aberta. O tal do hormônio. Agora tomo o chá da amora. (Elizete)

Relatos das mulheres apontam a abertura e valorização também por outros profissionais de saúde acerca do uso de ervas medicinais:

Tinha uma enfermeira que vinha aqui logo no começo [...] que ela me ensinou o chá, no caso, pra mim tá usando pra ajudar. Porque eu sou hipertensa, né. Ela falou, faz o chá da casca do abacaxi, faz o chá de algumas coisas, assim, pra tá ajudando. (Jisele)

Estes achados no assentamento, por um lado, se contrapõem aos resultados de pesquisas que mostraram, por exemplo, que a abertura a tais práticas se dá mais entre agentes comunitários de saúde do que profissionais de nível superior, como a de Matos e $\mathrm{Greco}^{28}$. Por outro lado, corroboram os resultados de pesquisa que mostram uma receptividade de profissionais de saúde a tais práticas ${ }^{29}$.

Além das ervas medicinais usadas em curativos, chás, banhos, xaropes e outros tipos de remédios, adotam-se alguns cuidados especiais com a alimentação, incorporando em suas dietas alguns alimentos com propriedades específicas (como a linhaça) capazes de auxiliar no tratamento e prevenção de algumas doenças (no caso da linhaça, para o colesterol alto).

Foi possível perceber que nem todas as mulheres adotam práticas populares de cuidado à saúde, às vezes nem mesmo as aceitam. Algumas se mostram contrárias à utilização de alguns recursos, enquanto outras são entusiastas da utilização dessas práticas.

A gente não pode deixar as ervas medicinais, não é? A gente não pode deixar! Não pode! Não pode nunca desprezar, né! (Elizete)

Alguns relatos mostram ainda uma possível hierarquização do saber, fazendo com que o conhecimento popular seja legitimado com a aprovação e o reconhecimento dos profissionais da saúde.

Daí aquelas antigas, tipo minha sogra e a avó do meu marido falavam as coisas e eu não seguia nada, eu falava, gente, por favor, saiam daqui! Deixa eu ver o que eu vou fazer. Porque queriam [...] que eu 
colocasse maisena no bumbum, eu também não coloquei [...] Eu não queria ficar ouvindo muito, eu sempre queria a opinião mesmo de um médico. (Leonilda)

O Doutor lá de Araraquara, ele é um pediatra muito bom. Se a minha netinha só tá assada ele fala:

"Maisena!" É maisena direto. Põe na água, minha filha, põe no banho. (Jisele)

Leonilda, que é Agente Comunitária de Saúde, não aceitava as sugestões de cuidados feitas por sua sogra e pela avó de seu marido por não saber se essas práticas eram benéficas ou prejudiciais para seu filho. Sentia-se mais segura quando um médico ou médica recomendava o mesmo cuidado. Ela não utilizava os recursos naturais que tinha em seu quintal no cuidado à saúde, passando a usá-los após ter recebido orientação médica, colocando-a em prática para verificar sua eficácia.

Eu cheguei a usar algumas coisas assim, eu tinha criança pequena na época e ele (o médico) dizia: "Não, ao invés de você passar aqui na farmácia e pegar um expectorante, você vai na casa do Donizete que o pai dele tem Caraguatá, e faz o chá. É aquela frutinha [...]" Eu não gostava muito não, eu nunca fui de botá muita fé nessas coisas. Eu não era dessas práticas de chá, não. Mas eu fiz a experiência que ele ensinou e funcionou mesmo. (Leonilda)

O ACS ocupa posição singular e contraditória no trabalho em saúde na Atenção Básica: por um lado, é membro da comunidade a ser atendida pelo serviço de saúde, sendo também usuário destes serviços; por outro, torna-se integrante, nem sempre legitimado, de uma equipe de saúde. Desta forma, conhece e enfrenta as mesmas dificuldades de acesso e de resolubilidade que perpassam o sistema público de saúde, enquanto faz parte de um serviço cujo processo de trabalho tende a reproduzir, de forma também contraditória, a divisão social do trabalho e as disputas em torno dos projetos terapêuticos ${ }^{30}$.

No trabalho dos ACS, é frequente que encontrem situações relativas a problemas de saúde comuns, para cujo enfrentamento existe abundância de informações preventivas, mas que persistem, e cujas causas vão além da capacidade de resposta por meio de ações individuais ${ }^{30}$.

\section{Aprendendo e ensinando práticas de cuidado à saúde.}

Para Vanderleia, o cuidado se aprende na relação com o outro. Ela diz ter aprendido muita coisa sobre saúde nas capacitações para ser agente comunitária, mas reconhece que muito do que aprendeu foi consolidado no cotidiano e no convívio tanto com as famílias para quem presta assistência, como com sua própria família.

[...] essa dedicação com o outro, eu acho que é uma troca, porque é a família da gente, eles se preocupam com a gente, entendeu. Eu acho que é uma troca, o cuidado é uma troca. A gente aprende na escola, televisão. Eu sou ACS, então é treinamento, capacitação. Então, a gente foi tendo muita informação. Coisa que há 12 anos eu não sabia, hoje eu sei. Pai e mãe. (Vanderleia)

Percebe-se nessa fala como a agente comunitária integra os diversos saberes no seu planejamento do cuidado, no conhecimento que mobiliza para tal, como nos mostram Stotz, David e Bornstein ${ }^{31}$, referindo-se ao trabalho do agente comunitário de saúde:

Numa abordagem que se baseia numa concepção ampliada de saúde, a centralidade do processo está no diálogo, na conversa, na busca de conhecer a vida das pessoas e seus problemas, antes de partir para a divulgação de orientações. [...] A concepção ampliada de saúde se aproxima da educação popular em saúde: considera o saber comum das pessoas sobre a experiência de adoecimento e de cura, adquirido através de sua história de vida e de sua cultura, o ponto de partida do processo educativo ${ }^{31}$. 
É importante reconhecer que uma relação pedagógica transformadora não está dada apenas pelo exercício da vontade individual deste ou daquele agente. Depende das possibilidades abertas pelas inovações trazidas pela estratégia de Saúde da Família ${ }^{31}$.

A atividade profissional das Agentes Comunitárias é vista como uma atividade de cuidado que é também educativa. Dizem que nesse processo de cuidar, ensinam e aprendem na dialogicidade.

Eu aprendi muito, eu tive que aprender, porque eu não sabia. Às vezes me chamam de muito curiosa, porque eu tenho muita vontade de aprender. Mas eu vejo assim, eu tenho que aprender pra transmitir, porque uma agente comunitária não tem um curso técnico, não tem né, a gente sabe que a gente vai aprender com a prática. (Leonilda)

Mas hoje o que a gente tem de conhecimento pra tá passando a respeito de uma gestante, do cuidado com a boca, que é uma saúde geral. Aí, a gente tem e a gente aprende muito com quem a gente vai ensinar também. As práticas deles, o que eles conseguiram mudar, né. (Flávia)

Esses e outros relatos reforçam a importância dos profissionais de saúde conhecerem e reconhecerem as práticas populares, oferecendo recursos de cuidados acessíveis e adequados a cada contexto e população. A postura dialógica abre espaço para o relato de tais práticas no encontro com o profissional de saúde, que, por sua vez, abre caminhos para um plano de cuidados inclusivo da cultura popular. Postura não dialógica, como relatado por Teixeira, Lin e Martins ${ }^{32}$, leva ao silenciamento em relação ao uso de tais práticas, pois os pacientes antecipam uma resposta desaprovadora, seguida de desinteresse e descrédito por parte dos profissionais.

Ainda no âmbito da aprendizagem nas relações, as intergeracionais foram frequentemente citadas como educativas:

[...] às vezes a gente reclama de tudo. Às vezes eu chegava em casa e reclamava, só tem isso de mistura, arroz e feijão, um ovo frito. Aí, ele falava: "É, e antigamente não tinha nem isso pra comer..." Meu pai sempre falava "nunca reclama, se você pegar uma banana pra comer, se você jogar a casca, vai vir alguém atrás pra pegar aquela casca". (Preta)

[...] eu adoro sentar perto dessas pessoas mais idosas pra ouvir as histórias, me comove. (Preta)

Relações intergeracionais também foram apontadas por Loyola ${ }^{27}$ como sendo processos pelos quais as mulheres que exerciam práticas populares adquiriram conhecimentos e incentivos, mais especificamente, a autora refere o contato com mulheres mais experientes, quase sempre pertencentes ao seu grupo familiar.

A busca pela legitimidade das práticas populares também se revela como um processo educativo, como se verá a seguir, no relato de Marli, sobre um tratamento medicamentoso que fez para controlar o colesterol alto, dizendo que a medicação lhe fazia muito mal. Ao ir conversar com o médico sobre os efeitos colaterais da medicação, fizeram outro exame e, apesar do colesterol estar alterado, o médico considerou que seria melhor suspender a medicação que a prejudicava, porque o resultado do exame mostrava que seus índices de colesterol estavam próximos dos valores de referência. Marli, então, diz ter ficado preocupada com o colesterol e, na conversa com uma amiga, esta lhe disse que consumir sementes de linhaça regularmente ajudava a emagrecer. Passou, então, a consumir tais sementes e, após ler em uma revista que o consumo da semente de linhaça regulariza os níveis de colesterol no sangue, fez novamente os exames e constatou que o seu índice de colesterol estava baixo.

Mas então, eu acho assim, eu só parei de tomar porque eu comprovei que realmente a semente de linhaça resolveu. [...] eu fiz o exame, deu alterado, mas era pouquinha coisa, então ele achou que não precisava entrar com medicamento. Aí eu comecei a usar, falei com ele e ele mandou eu parar com a Sinvastatina, não me passou nada. Daí eu fiz a semente de linhaça que me ensinaram. Daí eu repeti o exame e tava baixo. (Marli) 
É, eu li sobre ela! Eu aprendi que ela queima a gordura, essas coisas, ela age como diurético, faz o intestino funcionar melhor. (Marli)

Marli buscou comprovar por exames que a linhaça estava resolvendo seu problema de saúde e esse esforço configura-se como mais um exemplo da busca pela legitimidade dos tratamentos. Nessa busca, as mulheres recorrem a diversas fontes de saberes para sentirem-se seguras com as escolhas que fazem para cuidar de sua própria saúde, além da saúde dos demais. Elas trocam informações sobre as práticas de saúde que conhecem, procuram livros e revistas, profissionais da saúde e fazem exames. E assim aprendem mais sobre as práticas populares de saúde, reforçando seus argumentos a favor desse uso.

Algumas dizem aprender muito lendo livros ou revistas, citando o livro "Medicina Alternativa de A a Z"(g), assim como revistas que ensinam dietas, receitas e dicas de beleza de modo geral, como diz Marli

Não lembro não, acho que vi em revista mesmo, essas de coisas naturais.
Além disso, programas televisivos são muito citados

Eu vi numa reportagem do Globo Repórter. Sempre que fala sobre saúde eu vejo. Eu gosto muito. Acho que aborda uns temas bem legais. Nossa, eu já aprendi muito [...] (Jisele)

E assim, consultando diversas fontes de informação, trocando informações entre elas e com os profissionais de saúde, as mulheres vão ensinando e aprendendo sobre o cuidado e sobre as práticas populares de saúde, assim como fazendo suas escolhas com consciência, optando por aquelas que avaliam serem as mais eficazes, adequadas para as particularidades de cada uma delas e também das demais pessoas da comunidade onde moram e atuam.

\section{Considerações finais}

Esta pesquisa se configurou na perspectiva da Educação Popular e Saúde por seu intento em conhecer e divulgar os saberes das mulheres camponesas tanto relativos à saúde, como também relativos aos mecanismos de luta e resistência das camponesas na busca pela promoção do bem-estar pessoal e coletivo.

Como desafios político-pedagógicos à educação popular em saúde que emergem desta experiência de mulheres camponesas, apontamos, em concordância com Daron ${ }^{8}$ : o desafio de construção de um sistema público de saúde mais democrático, capaz de ouvir a população e de cuidar das pessoas enquanto sujeitos, enfrentando as causas das doenças e articulando atores que possibilitem a intersetorialidade; e o desafio de implementar a exigência ética de reconhecimento e fortalecimento das práticas populares tradicionais e integrativas de saúde como formas de atenção à saúde que precisam de reconhecimento nas políticas públicas para repensar as políticas de saúde, deixando de serem vistas como práticas marginais e tornando-se, enfim, legítimas ao dar centralidade ao cuidado.

Dentro do seu escopo e objetivos, a pesquisa possibilitou identificar a falta de atividades voltadas para as mulheres do assentamento como um importante fator de agravo à saúde integral da mulher camponesa. Em contrapartida, esse mesmo (g) Spethmann, Carlos Nascimento. Medicina Alternativa de $\mathrm{A}$ a Z. Editora Edições Natureza. 392 p. ISBN: 85-320-1967-6. 
grupo de mulheres refere perceber melhoras na qualidade de vida das que se envolveram em atividades como cursos, grupos de discussões sobre a realidade no campo e na comunidade onde vivem, reuniões dos movimentos sociais, entre outras. As práticas de cuidado à saúde no Assentamento Monte Alegre perpassam por diversas atividades, como a produção e o uso de remédios caseiros, o diálogo, o companheirismo, a escuta ativa, as mobilizações e ações políticas promovidas por elas mesmas, além da própria educação em saúde praticada por todas em seus cotidianos, integrada às demais ações. Também foram mencionadas as práticas de assistência multiprofissional oferecidas pelos serviços de saúde e as visitas domiciliares.

Além dessas práticas desveladas neste estudo, relatadas no parágrafo acima, que mostram que essas mulheres vêm buscando novas estratégias para se articularem e proporcionarem novos espaços de trocas de experiências, com o intuito de fortalecer sua comunidade, outras ainda puderam ser identificadas nessa mesma direção. As mulheres promovem ações educativas sobre cuidados com a saúde, encontros na comunidade para estimularem empreendimentos solidários, grupos para atividades artesanais, entre outros. Tais estratégias são realizadas no assentamento para a população local, mas também em outros espaços, como nas praças da cidade; no terminal rodoviário; em outros assentamentos, para outros grupos de camponesas; fortalecendo ainda mais a expressão da população do campo.

Conhecer o cotidiano dessas mulheres, seus saberes de experiência, suas compreensões de saúde, suas práticas populares de cuidado à saúde e seus processos educativos abre possibilidades de ampliação das compreensões sobre as necessidades de saúde da mulher camponesa, o que potencializa novas investigações e a criação de novas estratégias no campo da atenção à saúde no SUS, com o intuito de ampliar a inclusão e diálogo com as compreensões e com os modos populares de cuidar da saúde.

\section{Referências}

1. Ayres JRCM. Cuidado e reconstrução das práticas de saúde. Interface (Botucatu). 2004;8(14):73-92. http://dx.doi.org/10.1590/S1414-3283200400010000

2. Riquinho DL, Gerhardt TE. A transitoriedade nos estados de saúde e doença: construção do cotidiano individual e coletivo em uma comunidade rural. Trab Educ Saúde (Online). 2010;8(3):419-37. http://dx.doi.org/10.1590/S1981-77462010000300005

3. Borges JRP, Fabro ALD, Ferreira P. Condições de vida e qualidade do saneamento ambiental em assentamentos da reforma agrária paulista: Representações e práticas cotidianas. In: Anais do 150 Encontro Nacional de Estudos Populares; 2006; Caxambú-MG. São Paulo: ANPED; 2006.

4. Morissawa M. A história da luta pela terra e o MST. São Paulo: Expressão Popular; 2001.

5. Pedrosa JIS. Cultura popular e identificação comunitária: práticas populares no cuidado à saúde. In: Fonseca AF, organizador. Educação e saúde. Rio de Janeiro: Fiocruz; 2007.

6. Coelho EAC, Silva CTO, Oliveira JF, Almeida MS. Integralidade do cuidado à saúde da mulher: limites na prática profissional. Esc Anna Nery Rev Enferm. 2009;13(1):154-60.

7. Sales C MV. Mulheres rurais: tecendo novas relações e reconhecendo direitos. Estud Fem. 2007;15(2). http://dx.doi.org/10.1590/S0104-026X2007000200010

8. Daron V. A dimensão educativa da luta por saúde no Movimento de Mulheres Camponesas e os desafios político-pedagógicos para a educação popular em saúde. Cadernos CEDES., 2009;29(79):387-99. Disponível em: <http://www.cedes.unicamp.br>.

9. Minayo MCS. O desafio do conhecimento: pesquisa qualitativa em saúde. 8a ed. São Paulo: Hucitec; 2004.

10. Laplantine E. Antropologia da doença. São Paulo: Martins Fontes; 1991. 
11. Scopinho R A. Condições de vida e saúde do trabalhador em assentamento rural. Ciênc Saúde Colet. 2010;15 supl 1:1575-84. http://dx.doi.org/10.1590/S1413-81232010000700069

12. Dussel E. Filosofia de la liberación desde la práxis de los oprimidos. Rev LiberaciónLibertação (Campo Grande). 1991;2:33-49.

13. Oliveira MW, Moraes JV. Práticas populares de saúde e a saúde da mulher. Rev APS. 2010;13(4):412-20.

14. Queiroz MS. Representações sobre saúde e doença: agentes de cura e pacientes no contexto do SUDS. Campinas: Editora da Unicamp; 1991.

15. Teixeira IMC. Saberes e práticas populares de saúde: os processos educativos de mulheres camponesas [dissertação]. São Carlos: Universidade Federal de São Carlos; 2012.

16. Campoi AM. Sistemas de produção e estratégias de vida para a permanência na terra: um estudo no projeto de assentamento Monte Alegre - Araraquara-SP [mestrado]. Araraquara: Centro Universitário de Araraquara; 2005.

17. Ferrante VLB. Assentamentos rurais: estratégias de recusa ao modelo estatal? Raízes. 2000;(15):62-76.

18. Gaspari LC. Estratégias familiares e sustentabilidade econômica em assentamento rural [dissertação]. Araras: Universidade Federal de São Carlos; 2010.

19. Bodgan R, Biklen S. Investigação qualitativa em educação: uma introdução à teoria e aos métodos. Portugal: Porto; 1994. (Coleção ciências da educação)

20. Ezpeleta J, Rockwell E. Pesquisa participante. São Paulo: Cortez; 1989.

21. Vázquez-Navarrete ML, Silva MRF, Pérez ASM, Sanmamed MJF, Gallego MED, Lorenzo IV, organizadores. Introdução às técnicas qualitativas de pesquisa aplicadas em saúde. Recife: Instituto de Medicina Integral Professor Fernando Figueira; 2009.

22. Bardin L. Análise de conteúdo. Lisboa: Edições 70; 2008.

23. Silva GF. A natureza educativa nas ocupações de luta pela terra no Brasil. Libertas. 2007; ed esp:50-67.

24. Freire P. Pedagogia do oprimido. Rio de Janeiro: Paz e Terra; 1987.

25. Fiori EM. Conscientização e educação. Rev Educ Realidade. 1986;11(1):3-10.

26. Oliveira MW, Stotz EN. Perspectivas de diálogo entre organizações governamentais e não governamentais e instituição acadêmica: o convívio metodológico. In: Sociedade, democracia e educação: qual universidade? Anais da 27a Reunião da ANPEd. 2004; 21-24 nov 2004; Caxambu-MG. São Paulo: associação Nacional de Pós-graduação e Pesquisa em Educação; 2004.

27. Loyola MA. Médicos e curandeiros: conflito social e saúde. São Paulo: Difel; 1984.

28. Matos I, Greco RM. Curandeirismo e saúde da família: conviver é possível? Revista APS. 2005;8(1):4-14.

29. Alvim NA, Cabral IE. Saberes e práticas de enfermeiras sobre plantas medicinais: um exercício de análise com categorias bakhtinianas. Acta Paul. Enf. 2004;17(1):70-8.

30. Bornstein VJ, Stotz EN. O trabalho dos agentes comunitários de saúde: entre a mediação convencedora e a transformadora. Trab Educ Saúde. 2009;6(3):457-80.

31. Stotz EM, David HMSL, Bornstein VJ. O agente comunitário de saúde como mediador: uma reflexão na perspectiva da educação popular em saúde. Rev APS. 2009;12(4):487-97.

32. Teixeira MZ, Lin CA, Martins MA. O ensino de práticas não-convencionais em saúde nas faculdades de medicina: panorama mundial e perspectivas brasileiras. Rev Bras Educ Méd. 2004;28(1):51-60. 
Teixeira IMC, Oliveira MW. Prácticas de atencion en la salud de las mujeres campesinas. Interface (Botucatu). 2014; 18 Supl 2: 1341-1354.

Este artículo presenta los resultados de la investigación de las prácticas de atención de la salud de mujeres campesinas del asentamiento Monte Alegre VI - SP. La metodología cualitativa, consistió en la observación de participante y entrevistas, se realizaron 15 visitas entre abril de 2010 y julio de 2011. Participaron doce mujeres, entre las cuales había seis agentes comunitarias de la salud. Las prácticas de cuidado se refieren a: el compañerismo, el diálogo, la escucha activa, la movilización social, los servicios de salud multidisciplinarios, el uso de las plantas medicinales, las creencias religiosas y las dietas. Estas prácticas se suman y se articulan. Las participantes enseñan y aprenden sobre el cuidado en las relaciones entre ellas, las inter-generacionales y en las relaciones con los profesionales de la salud, además de recurrir a otras fuentes de información y otros procesos de formación específicos, como PSF.

Palavras clave: Educación popular y salud. Cuidado de la salud. Salud de la población rural. Prácticas populares de salud. Procesos educativos 